\title{
Comparing physical to virtual: fit and appearance of multi-layered cultural garments
}

\begin{abstract}
This study sought to expand the use of virtual technology to include multi-layered nonwestern cultural garments and compare these complex garments, physically and virtually. In addition, 3D simulation of non-western garments could benefit the emerging Chinese market. The study included five parts: material selection, avatar customization, physical multi-layered garment construction, virtual multi-layered garment construction, and evaluation of the physical and virtual garment appearance and fit using an online survey. This study found that multi-layered cultural garments could be relatively effectively simulated in virtual software, such as EFI Optitex. Moreover, number of fabric layers did not significantly affect either appearance or fit similarity between virtual and physical garments. Based on these results, it can be concluded that virtual presentation has great potential as a tool to evaluate the appearance of a garment in a relatively simple and quick way.
\end{abstract}

Keywords: fit, appearance, garments, 3D virtual prototyping, culture, fashions, apparel
Volume 6 Issue 2 - 2020

\section{Bai Li, Kelly Cobb, Huantian Cao}

Department of Fashion and Apparel Studies, The University of Delaware, USA

Correspondence: Kelly Cobb, Department of Fashion and Apparel Studies, The University of Delaware, USA, Tel 302-8316132,Emailkcobb@udel.edu

Received: March 06, 2020| Published: April 07, 2020

\section{Introduction}

The traditional model of apparel product development requires multiple sample revisions. Industry wide, 3D virtual prototyping is being adopted as an innovative model of product development, promoting better communication of design throughout the supply chain. As a tool to evaluate the appearance and fit of multi-layered garments, specifically Chinese cultural garments, 3D virtual prototyping have great potential. The market for traditional Chinese fashions, for example multi-layered garments such as Qipao and Hanfu, has blossomed in the past decade. The "Hanfu movement" as well as concerted efforts by China's government to promote traditional Chinese culture, are reshaping attitudes among those born after 1978 who are increasingly comfortable and willing to accept Chinese culture and cultural brands ${ }^{1,2} 3 \mathrm{D}$ simulation of multi-layered cultural garments could simplify the design process of cultural garments and have a positive influence on overall development of the emerging market in China.

At present, garment supply chains in China are complex and cumbersome. Designers in China create drafts in studios while the physical prototyping process is finished in factories, usually offshore, in Bangladesh, Turkey, or other manufacturing counties. Then, apparel prototypes are shipped back to the studios in China to be rejected, edited, and sent back to factories, with comments for improvement. ${ }^{3}$ This cycle repeats until the design is accepted by designers, making the supply chain inefficient and increasing sample waste. Virtual prototyping technology can help the apparel industry eliminate the need for multiple physical apparel samples. This will save valuable time and reduce a product's overall carbon footprint. ${ }^{4}$

This study expands the use of virtual technology to multi-layered non-western cultural garments both physically and virtually. Cultural garments, Qipao (tight fit) and Hanfu (loose fit), were constructed and produced to investigate the appearance and fit of virtual and physical garments based on existing patterns. The procedure involved measuring the physical parameters of the fabric, customizing an Optitex
EFI Fabric Library, developing 2D and 3D patterns via EFI Optitex pattern drafting software, creating physical and virtual garments, and conducting an on-campus survey. The survey provided feedback on the appearance and fit of virtual and physical garments. An evaluation of how virtual prototyping technologies can help designers and pattern makers tailor the appearance and fit of multi-layered cultural garments is an important contribution to the fashion industry's business model and its ability to operate in an environmentally-friendly manner.

\section{Literature review}

Virtual prototyping technologies are currently widely used in the development of many materials, processes, and products in engineering industries such as automotive and interior design. By integrating $3 \mathrm{D}$ virtual prototyping technologies into manufacturing process, brands can effectively lessen negative impact generated during the manufacture of physical prototypes. Specifically, the $3 \mathrm{D}$ virtual prototyping technologies can cut down the time spent obtaining the raw materials and constructing samples. Moreover, there is potential for virtual prototyping technologies to be applied to apparel and footwear industries.

Virtual prototyping is an emerging technology, which "creates product prototypes using computer-generated virtual reality and the manufacturer's engineering data" ${ }^{5,6}$ Compared to physical prototyping, 2D pattern modification can be simultaneously reflected on the simulation of the 3D garments during the virtual prototyping process. ${ }^{7}$ Virtual prototyping is a $2 \mathrm{D}$-to-3D approach. During the virtual prototyping process, designers sketch the $2 \mathrm{D}$ patterns, and later assemble the virtual garment through virtual stitching (sewing) processes to produce a virtual sample. ${ }^{7}$ Therefore, the virtual prototyping technologies allow designers to validate their product design.

A number of exploratory studies have been undertaken for 3D virtual design technologies. Baytar and Ashdown ${ }^{8}$ explored using 3D virtual design technologies and try-on technologies and found integrating them within the design process could impact sustainability 
in the creative stage, and open up a role for consumers as co-designers. ${ }^{9}$ Moreover, 3D simulation technologies have been used not only for manufacturing but also for e-commerce. Kim and Forsythe (2009) found that the $3 \mathrm{D}$ virtual prototyping can encourage consumers to visit retail websites. Park, Kim, and Sohn ${ }^{10}$ explored the effectiveness of $3 \mathrm{D}$ virtual prototyping technology for enhancing spatial visualization skills in apparel design education. They found that 3D simulation technology has positive potential as a useful instructional tool for improving students' visualization skills in apparel design. ${ }^{10}$

One key to validating the usefulness of 3D simulation technology in fashion design is ensuring the fit of virtual designs approximates the actual fit of garments. Several researchers have analyzed and verified virtual fit information for garments. Naglic, Petrak, \&Stjepanovic ${ }^{11}$ made the virtual fit of a female diving suit, which was created by using the 3D flattening method, in static and dynamic body postures. Rudolf et al. ${ }^{12}$ examined the important parameters regarding the similarity between real and virtual garments. They pointed out it is essential that fabric drapes need to be the same as real fabrics. Lim $^{13}$ compared virtual simulations of women's wear produced in two different systems, namely OptiTex and Vstitcher, utilizing identical material properties and found that visual appearance of simulated garments differed in two systems. Additionally, Ancutiene and Sinkeviciute ${ }^{14}$ proved that the $3 \mathrm{D}$ virtual simulation system could fit differently on the human body, based on measuring distance ease and strain. In other words, closing the gap between virtual fit and actual fit is still a work in progress.

To enable virtual garment simulation, two factors are paramount: accurate representation of the human form and realistic cloth simulation. ${ }^{15}$ Also, Luible and Magnenat-Thalmann ${ }^{16}$ explained that the true representation of a virtual garment is dependent on precise computational models and exact input of fabric parameters. Recently, one study proposed an automatic virtual garment transfer system for human models of various shapes and poses, focusing on the realistic fitting result while preserving the original garment size. ${ }^{17}$ During the garment simulation process, the quality of virtual garments can be described by aesthetic appearances, such as its drape and fit quality. ${ }^{18}$ Kim and LaBat ${ }^{19}$ investigated the fidelity and accuracy of 3D garment simulation technology used in the online market. They used rating scales for the number of critical fit locations was often used to measure both wear and expert evaluations of garment fit. One study ${ }^{12}$ tested the influence of parameters on the accuracy of virtual garments' drape quality to achieve better realistic appearances of virtual garments. Kim et al. ${ }^{20}$ analyzed the similarity of fit and appearance between real and virtual torso length sloper.

One significant challenge for $3 \mathrm{D}$ virtual simulation programs is that fabric drape simulations have a limited ability to produce accurate virtual representations of particular fabrics. ${ }^{21}$ The fabric measurement methods and derivation of fabric parameters need to be improved. ${ }^{16}$ Power et al. ${ }^{15}$ introduced methods of obtaining fabric mechanical and physical properties, such as FAST and KES-F. Moreover, Power $^{22}$ compared and interpreted the difference for six knitted fabrics. Moreover, there has been no systematic investigation on the validity of $3 \mathrm{D}$ clothing simulation for fit analysis, especially given the diversity of fabric properties..$^{23}$ Specifically, Sayem and Bednall ${ }^{24}$ investigated the correlation between the change in virtual drape parameters (tension, stretch, and pressure) and the change in fitting ease of blouse. They found this correlation can lead to a development of 3D virtual garment simulation technology. Rudolf et al. ${ }^{12}$ found that soft bending on the virtual fabrics' drape simulations is essential, and without soft bending, the drape simulations of the garments would be inaccurate.

Progress in the application of 3D clothing simulation to singlelayer garments has come a long way; however, multi-layered garment simulation is still a difficult challenge. At present, 3D virtual prototyping technologies use a Physically Based Simulation method to construct the multi-layered garments, layer by layer. However, preparing a character dressed in multiple layers of garments can be very time-consuming and tedious. ${ }^{25}$ Also, in multi-layer virtual garment development, the under-layer fabric sometimes appears across the upper-layer fabric, resulting in a technical problem, penetration. $\mathrm{Hu}$, Wang, and $\mathrm{Zhou}^{26}$ explained that at the beginning of the virtual dressing with the existing garments, the effect of penetration always appears. Lazunin and Savchenko ${ }^{27}$ found similarly that current 3D virtual prototyping technologies do not work in situations where several layers' interlock: for example, a shoelace in a shoe.

$\mathrm{Hu}$, Wang, and Zhou ${ }^{26}$ designed a simple system based on physical simulation models. Also, they developed a computing algorithm to resolve the penetration problem that appears among multi-layered garments. Hu, Komura, Holden, and Zhong ${ }^{25}$ presented a novel scanning-based solution for modeling and animating characters wearing multiple layers of clothes. Lazunin and Savchenko ${ }^{27}$ proposed a non-iterative approach to the visually plausible rendering of multilayered clothes. Specifically, they developed a visualization technique to complement existing physically based methods. ${ }^{27}$ However, these studies did not verify the virtual fit, appearance, and fabrication characteristics of virtually simulated multi-layered garments.

The reemergence of traditional clothing in China over the past decade has created an opportunity to employ 3D technology in an entirely new arena. Although most of the cultural clothes in China are no longer worn as everyday garments, these styles have gained new consumers types, renewed global recognition, and powerful symbolic meanings. ${ }^{28}$ Only two studies have been done applying $3 \mathrm{D}$ virtual garment simulation in the design process of Hanfu and Qipao. One study described the method for design and implementation the virtual prototyping process for Qipao..$^{29}$ The other, conducted by $\mathrm{Ji}$ (2016) prototyped and verified 13 different kinds of Hanfu, and he built up the database of Hanfu classification for customer choice. As such, there is ample need for further investigation of how 3D garment simulation might be utilized within this market.

The purpose of the study was to expand the use of virtual technology to include multi-layered non-western cultural garments and to demonstrate comparisons of these complex garments, physically and virtually. Hypotheses for the study were as follows: H1: Fabric type significantly affects the appearance similarity in multi-layered cultural garments; H2: Design silhouette significantly affects the appearance similarity in multi-layered cultural garments; H3: Fabric type significantly affects the fit similarity in multi-layered cultural garments;H4: Design type significantly affects the fit similarity in multi-layered cultural garments.

\section{Methodology}

This study included five parts: material selection, avatar customization, physical multi-layered garment construction, virtual multi-layered garment construction, and evaluation of the physical and virtual garment appearance and fit using the online survey. The researcher adapted the traditional product design process, including virtual multi-layered garment construction (Shaeffer, 2012). Then, 
the researcher developed an evaluation survey to assess the hybrid garment design process. The customized multi-layered cultural garments developed by the researcher supported investigation of whether virtual technology can be expanded to non-western multilayered garments; they also frame the potential to evaluate appearance and fit using virtual garments, instead of assessing physical sample garments.

This study used a two-level factorial experiment in a complete $3 \times 2$ experimental design with two independent variables: fabric type and design. The independent variable fabric type has three levels: cotton, silk, and hemp. Another independent variable design status has two levels: Qipao (tight fit) and Hanfu (loose fit). The researcher assumed that two dependent variables, the overall similarity between virtual and physical garments, and the similarity between virtual and physical garments of critical areas would respond to the independent variables.

In Asia, traditional fabrics are constructed from natural fibers. Therefore, this researcher chose three natural fabrics (cotton, hemp, and silk) to construct multi-layered cultural garments. The cotton was obtained from China, and the hemp and silk were obtained from the U.S. (For detailed fabric measurements, see Table 1). Prior research determined that fabric properties affect garment appearance and fit. ${ }^{30}$ As such, in this study, Kawabata Measurement System (KES-F), Portable gauge (SDL.Atlas Inc., Rock Hill, SC, Model: J100), and a digital scale were used to test mechanical properties of selected fabrics in warp and weft directions.

Table I The textile characteristics for each fabric measured by the researcher

\begin{tabular}{llll}
\hline Fabric & Weight $\left(\mathbf{g} / \mathrm{m}^{2}\right)$ & Thickness $(\mathbf{m m})$ & Fabric Width \\
\hline Hemp & 185.833 & 0.465 & $53 "$ \\
Silk & 77.667 & 0.183 & $45 ”$ \\
Cotton & 121.583 & 0.296 & $/$ \\
\hline
\end{tabular}

The fabric objective measurements were tested in textile labs at the University of Delaware and Donghua University. The researcher prepared three $20 \mathrm{~cm} \times 20 \mathrm{~cm}$ square samples. Standard conditions for the test were $21^{\circ} \mathrm{C}$ and $65 \%$ relative humidity. The weight, thickness, and other mechanical properties of fabric were measured in interval level three times and the mean values were calculated. The weight was measured by a digital scale and the unit of measurement was $\mathrm{g} /$ $\mathrm{cm}^{2}$. The thickness was measured by a portable gauge (SDL Atlas Inc., Rock Hill, SC, Model: J100) and the unit of measurement was $\mathrm{mm}$. Other fabric properties such as the tensile, shear, bending, and surface properties were measured by KES-F system.

Using a standard size 8 misses and a customized virtual mannequin offered by EFI Optitex, the investigator took the measurements based on the ASTM D 5585-95 standard of the University of Delaware. The EFI Optitex software offered the dress form measurement standard. To gain the accurate measurement, the researcher measured the physical dress form three times. The measurements were entered into the EFI Optitex software (Figure 1) to finish the virtual avatar customization. Additionally, two Chinese cultural garments, Qipao (tight fit) and Hanfu (loose fit), were selected for this study. The researcher found the US size 8 Qipao pattern from a patternmaking book (New Look, 2018) and designed a no waste Hanfu pattern. Those 2D paper patterns were digitized into the EFI Optitex software using GTCO 3036 RollUP III Digitizer with 16-Button Cursor Model RD3-3036.

Next, the researcher constructed and produced cultural garments based on the patterns created. Before constructing the garments precisely, two muslin prototypes, Qipao and Hanfu in full size, were created to confirm the accuracy of the patterns. Physical garments were cut, assembled, sewn, and ironed in three different fabrics (cotton, silk, and hemp) by the researcher. With the process of dyeing fully garments (following instructions offered by iDye 2018), the garments were dyed blue. Therefore, all of the garments would be in same color. However, dying and washing garments may lead to shrinkage.

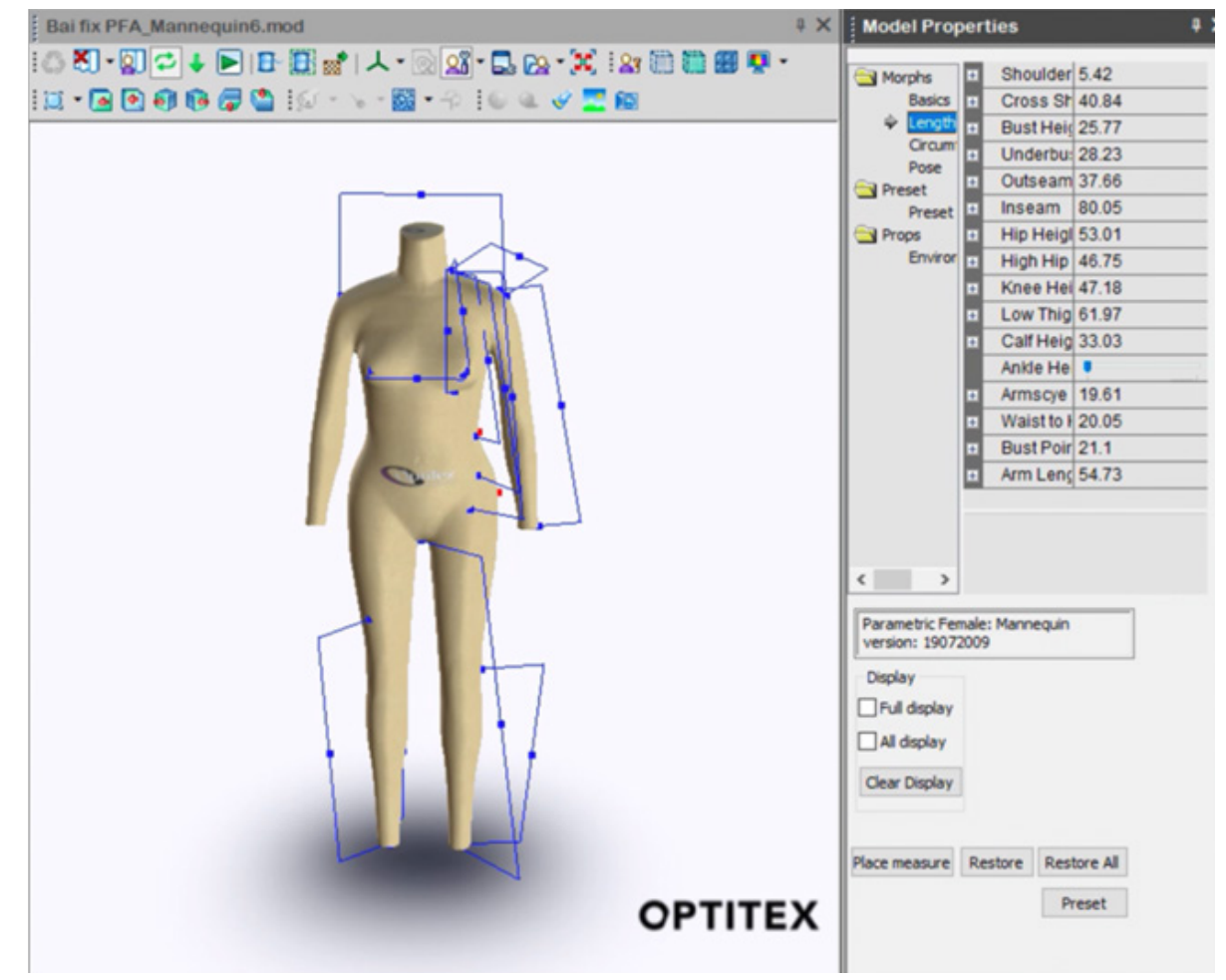

Figure I The measurements were entered into the EFI Optitex software to finish the virtual avatar customization. 
In total, the researcher developed six multi-layered cultural garments. To prepare for the appearance and fit evaluation survey, the researcher documented the garments photographically (digital camera) including front, side, and back views. The researcher then contacted four University of Delaware professors who teach large classes (more than 30 students). With the professors' assistance, the researcher sent the online survey link to the students while they were in class. The survey, as part of the coursework, was expected to take 15 minutes of the class time. The garments' evaluation questionnaire asked participants about the appearance and fit of critical areas and overall appearance and fit. In the survey's first section, the participants were asked to compare the overall physical garments (based on the images of the dress form in garments) to the overall virtual garments (based on the screenshots 3D virtual image). The participants used a 7-point Likert-type scale, which range from 1 (poor similarity) to 7 (excellent similarity). The second section asked participants to evaluate the similarity of 2 to 3 critical areas like sleeve, xiejin and collar using the 7-point Likert-type scale.

The Optitex index can be derived from KES-F parameters, using the fabric editor of EFI Optitex PDS 10 (Sayem, 2016). However, the fabric conversion tool is not available in the newest version of EFI Optitex. All KES-F data were converted into the EFI Optitex, (Table 2).

Table 2 Fabric properties conversion result

\begin{tabular}{llllllll}
\hline KES-F data & \multicolumn{2}{l}{ Fabric type } & \multicolumn{3}{l}{ Optitex index } & \multicolumn{3}{l}{ Fabric type } \\
\hline Parameters (Unit) & Cotton & Hemp & Silk & Parameters (Unit) & Cotton & Hemp & Silk \\
\hline EMT (\%) at warp & 0.95 & 1.01 & 1.96 & Stretch $(\mathrm{gr} / \mathrm{cm})$ at warp & 4.75 & 5.033 & 9.8 \\
EMT (\%) at weft & 3.53 & 2.33 & 3.18 & Stretch $(\mathrm{gr} / \mathrm{cm})$ at weft & 17.625 & 11.633 & 15.9 \\
Bending resistance B (cN) at warp & 0.1 & -0.25 & 0.05 & Bending $(\mathrm{dyn} * \mathrm{~cm})$ at warp & 96.825 & -242.11 & 53.563 \\
Bending resistance B (cN) at weft & 0.052 & 0.35 & 0.03 & Bending $(\mathrm{dyn} * \mathrm{~cm})$ at weft & 51.453 & 340.145 & 25.388 \\
Shearing resistance G (cN/(cm*deg)) & 3.15 & 0.68 & 0.26 & Shear $(\mathrm{dyn})$ & $180.48 \mid$ & 39.152 & 14.61 \\
Friction MIU & 0.13 & 0.1 & 0.12 & Friction & 0.132 & 0.1 & 0.118 \\
Thickness $(\mathrm{mm})$ & 0.296 & 0.465 & 0.183 & Thickness $(\mathrm{mm})$ & 0.296 & 0.465 & 0.183 \\
Weight $\left(\mathrm{g} / \mathrm{m}^{2}\right)$ & 121.58 & 185.83 & 77.667 & Weight $\left(\mathrm{g} / \mathrm{m}^{2}\right)$ & 121.583 & 185.833 & 77.667
\end{tabular}

\section{Results and discussion}

Ninety participants from the Fashion and Apparel Studies Department and eight students from other departments at the University of Delaware participated in the online survey. The students in the fashion department had a good knowledge of patternmaking and draping. IRB approval was acquired from University of Delaware IRB (HUMANS) on IRBNet before proceeding with the study. Most participants were undergraduates (93.9\%). These included $18.9 \%$ freshman $(n=17), 43.3 \%$ sophomore $(n=39)$ and $38.9 \%$ junior $(n=35)$. The responses were coded on 7-point scales ranging from 1 to 7 , with 1 being extremely poor similarity and 7 being excellent similarity. The variables of measurement are ordinal; however, in the fashion field, it is always treated as interval. The researcher designed a between-subjects $3 \times 2$ factorial design, investigating the effect of fabric type (cotton, hemp, silk) and designs (tight fit and loose fit) on the dependent variables. For fabric type, cotton was coded as 1 , hemp as 2, and silk as 3; and for design, tight fit was coded as 1 and loose fit as 2 .
The dependent variables for this study include: the overall appearance similarity between virtual and physical garments, the appearance similarity of critical areas between virtual and physical garments, the overall fit similarity between virtual and physical garments, and the fit similarity of critical areas between virtual and physical garments. The mean and standard deviation are shown in the following tables, but for the analysis purposes of this study only the relationship between the variables are described. As will be discussed below, the overall fit and appearance of the virtual garments was relatively acceptable. This study provided empirical support that multi-layered garments can be developed in 3D simulation software.

\section{Fabric selection}

The physical garments prototypes were constructed out of selected materials including cotton, hemp, and silk. The unit and meaning for the mechanical properties measured by KES-F index, which was used in this study, are shown in Table 3. Fabric properties were measured in interval levels. These properties were measured three times; the mean values and standard deviation were calculated (Table 3 ).

Table 3 Objective measuring results tested by KES-F for each fabric (Repeat testing for 3 times)

\begin{tabular}{|c|c|c|c|c|c|c|}
\hline \multirow{2}{*}{ Code } & \multicolumn{2}{|c|}{ Tensile resistance EMT (\%) } & \multicolumn{2}{|c|}{ Bending Resistance B (cN) } & \multirow{2}{*}{$\begin{array}{l}\text { Shearing resistance } \\
\mathrm{G}(\mathrm{cN} / \mathrm{cm} * \mathrm{deg})\end{array}$} & \multirow{2}{*}{$\begin{array}{l}\text { Friction } \\
\text { MIU }\end{array}$} \\
\hline & Warp & Weft & Warp & Weft & & \\
\hline Cotton & $0.95(.00)$ & $3.53(.26)$ & $0.10(.02)$ & $0.05(.00)$ & $3.15(.12)$ & $0.13(.00)$ \\
\hline Hemp & I.0I (.05) & $2.33(.16)$ & $-0.25(.29)$ & $0.35(.05)$ & $0.68(.30)$ & $0.01(.00)$ \\
\hline Silk & $1.96(.07)$ & $3.18(.16)$ & $0.05(.00)$ & $0.03(.00)$ & $0.26(.01)$ & $0.12(.00)$ \\
\hline
\end{tabular}

*M, means; SD, standard deviation in parenthesis 
EFI Optitex uses weight, stretch, shear, friction, bending, and thickness for garment simulation. In this study, the fabric properties were tested by the KES-F system. However, the standard for KES-F parameters and Optitex parameters are different, so a data conversion process was necessary to enter the data into the simulation software. The meaning of the KES-F index and EFI

\section{Virtual avatar customization}

A virtual dress form model provided by the EFI Optitex mannequin library was selected to reproduce the virtual avatar of American standard size 8 misses. In the EFI Optitex program, there are four morphing categories under model properties: basics, lengths, circumferences, and pose. Some criteria can be input as numerical values; others offer sliding bars. Specifically, some measurements are interrelated, so when one datum is changed, the other automatically changes with it according to the system software default settings. ${ }^{30}$ For example, the biceps and upper biceps are interrelated. ${ }^{30}$ This means that the data entered in the software is not always synonymous with the data that was measured by the researcher. After measuring the physical dress form three times, the researcher gained the measurements. The customized virtual dress form is shown in Figure 2

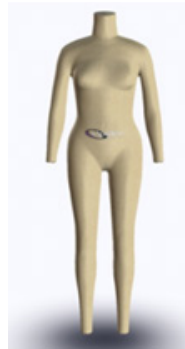

Front view

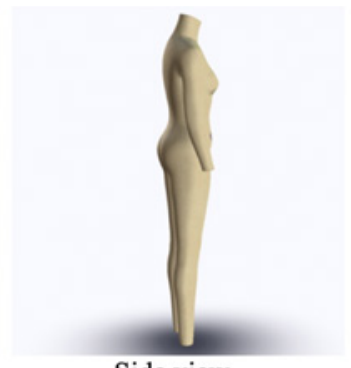

Side view

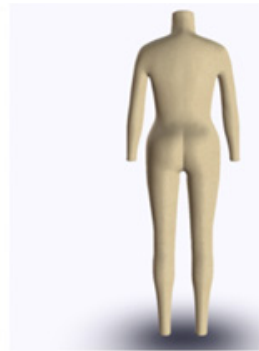

Back view
Figure 2 The customized virtual dress form.

\section{Physical multi-layered garment construction}

Classical-style Qipao and Hanfu were selected as physical garment silhouettes. Physical Qipao and Hanfu garments were constructed for size 8 misses, using full-scale printouts of the pattern from the patternmaking book (New Look, 2018) (Qipao) and from the digital pattern (Hanfu). The images of physical garments were documented on the same size 8 misses dress form. In this study, the Qipao was a short-length style, with a low collar, short sleeves, Xiejin, and no split. The collar has two layers, the Xiejin part has four layers, and the rest of the Qipao has one layer. The Hanfu has two layers: an inner dress and an overcoat. In addition, it has two design elements: collar and sleeve. The physical prototypes of the Qipao and Hanfu, which were produced from three fabrics, are represented in Figure 3.

\section{Virtual multi-layered garment construction}

The 2D patterns were either created or digitized into the EFI Optitex. The Hanfu pattern was customized in the software by the researcher, and the Qipao was digitized from a paper pattern found in a book (New Look, 2018). Within the 3D window, patterns were simulated on the virtual dress form. As presented in Figure 4, the researcher first defined the stitches and seamlines on the $2 \mathrm{D}$ pattern.

To create virtual multi-layered garments successfully, the researcher arranged the pieces in layers under the 3D properties dialog (Optitex, 2018). Layer 1 is the lowest and closest to the body (Optitex, 2018). In the process, the effect of penetration appears on the multi-layered garments. Following the suggestions of the EFI Optitex team, the researcher solved the penetration problem by modifying the resolution. The 3D garment is represented by a mesh made of triangles. Specifically, smaller triangle (high resolution) means more accuracy in representing the virtual garments, such as complex curved lines, folds, and wrinkle (Optitex Term, 2018). After setting a higher resolution, the penetration problem was solved. On the EFI Optitex platform, the virtual multi-layered cultural garments were constructed, which are presented in Figure 5.

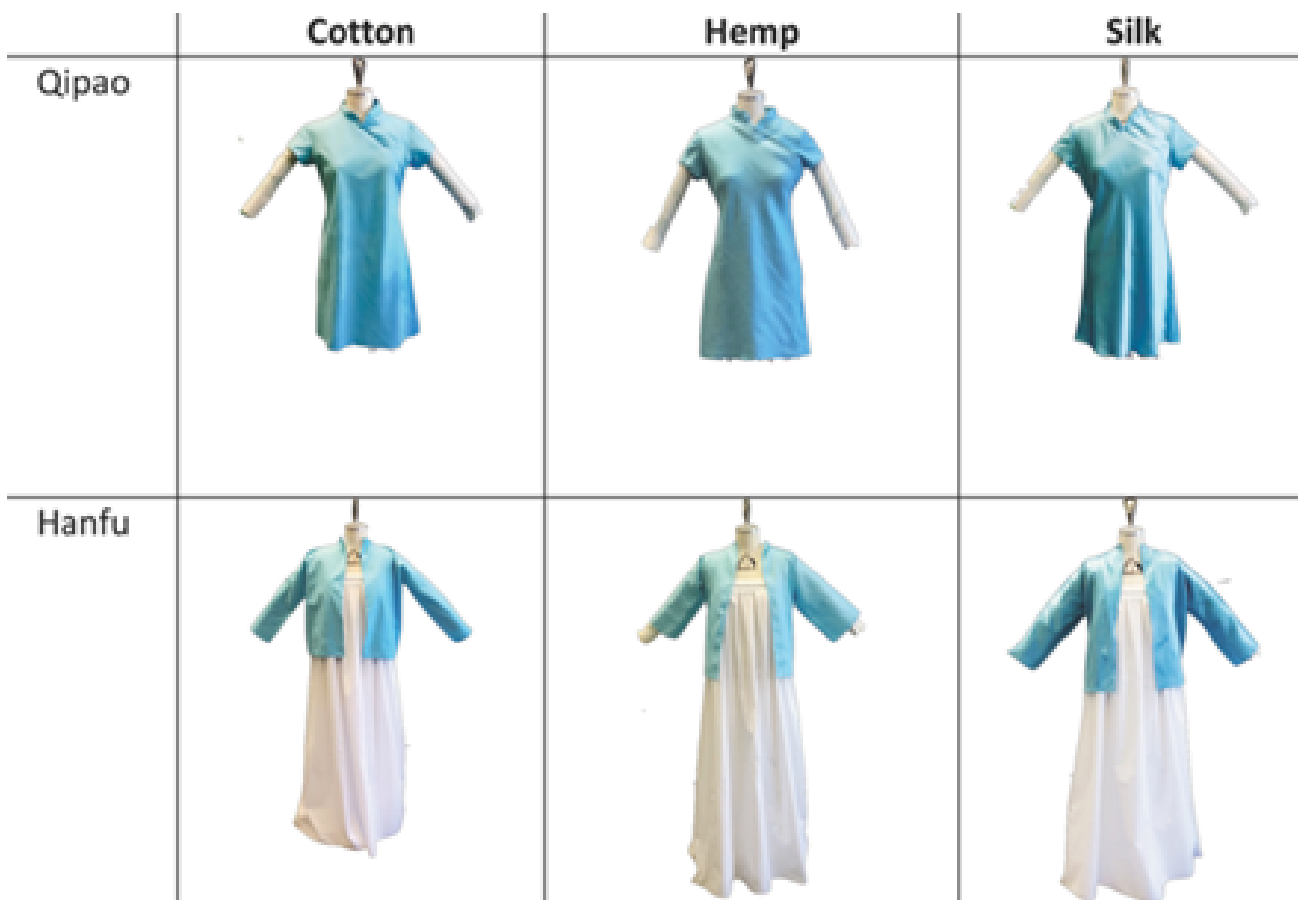

Figure 3 The physical prototypes of the Qipao and Hanfu, which were produced from three fabrics. 

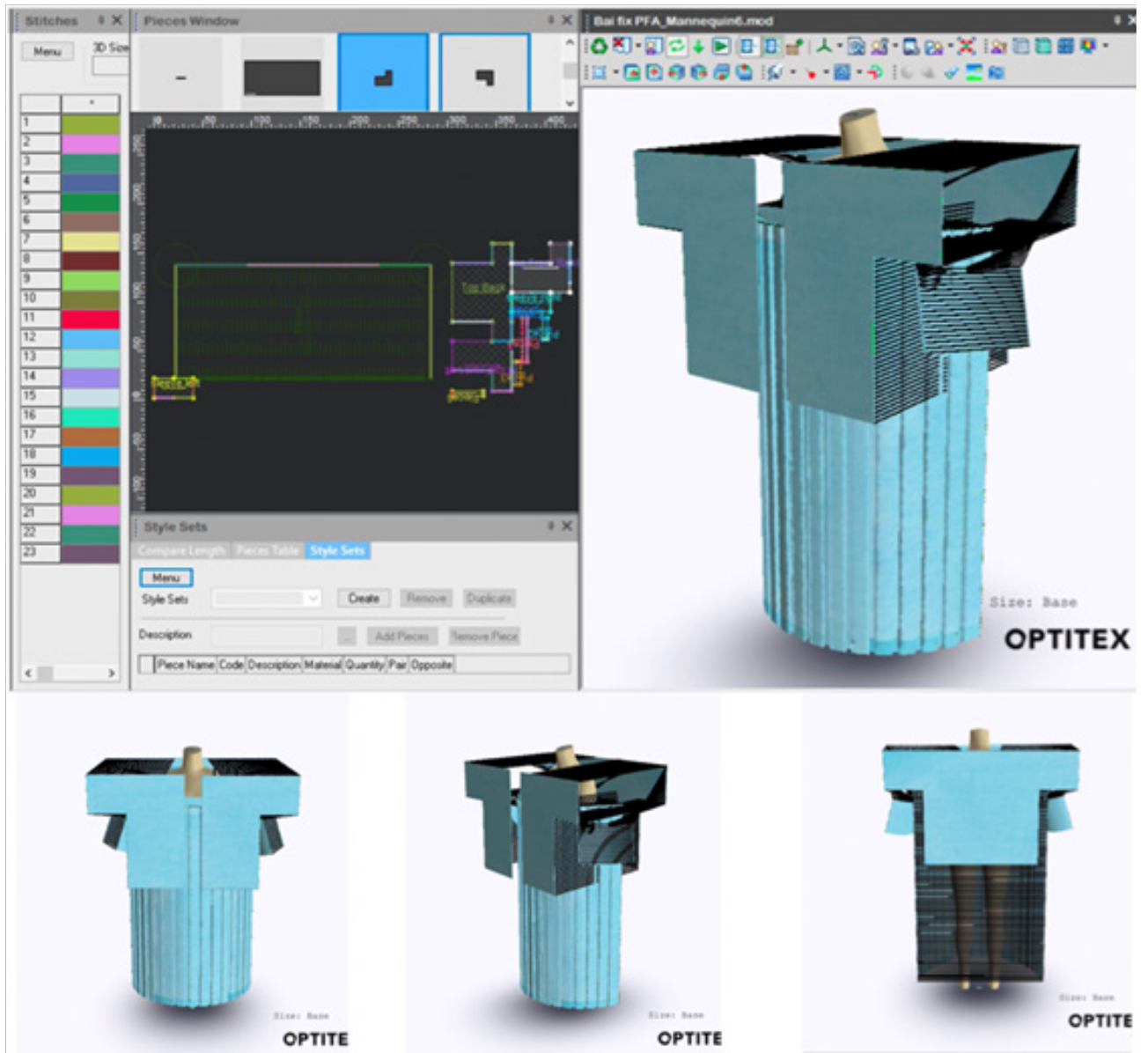

Figure 4 The definitions of stitches and seam lines.

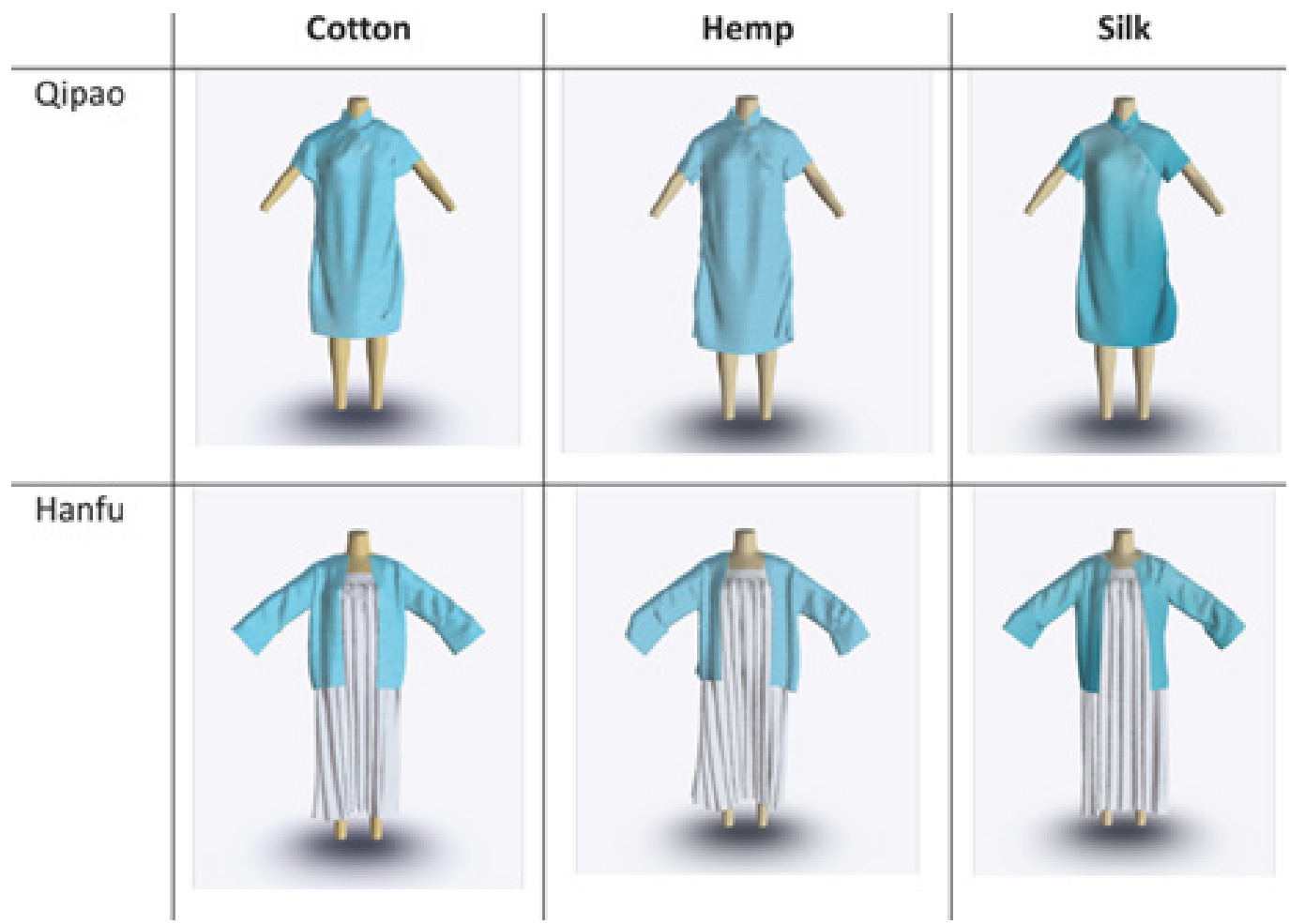

Figure 5 The virtual prototypes of Qipao and Hanfu, produced in Optitex EFI. 


\section{Appearance similarity qualitative analysis}

The mean and standard deviations data of appearance similarity quantitative analysis are presented in Table 4 and Table 5. The researcher analyzed appearance similarity and fit similarity individually. For testing $\mathrm{H} 1$ and $\mathrm{H} 2$, two-way ANOVA tests were conducted to examine whether the two independent variables, fabric and garment design, significantly affected the appearance similarity in multi-layered cultural garments. The p-values of these two-way ANOVA test results are in Table 6.

Table 4 The appearance similarity for descriptive statistics of front, side, and back views

\begin{tabular}{llll}
\hline \multirow{2}{*}{ Fabric } & View & Qipao & Hanfu \\
\cline { 3 - 4 } & & Mean (S.D.) & Mean (S.D.) \\
\hline \multirow{4}{*}{ Cotton } & Front & $4.30(1.30)$ & $4.63(1.50)$ \\
& Side & $3.90(1.30)$ & $4.47(1.50)$ \\
& Back & $4.09(1.50)$ & $4.42(1.40)$ \\
& Front & $4.07(1.40)$ & $3.93(1.50)$ \\
Hemp & Side & $3.90(1.50)$ & $4.09(1.50)$ \\
& Back & $4.26(1.20)$ & $3.70(1.40)$ \\
& Front & $4.11(1.40)$ & $4.39(1.60)$ \\
& Side & $4.03(1.40)$ & $4.20(1.50)$ \\
& Back & $4.24(1.50)$ & $4.27(1.50)$ \\
\hline
\end{tabular}

Table 5 The appearance similarity for descriptive statistic of different design points

\begin{tabular}{|c|c|c|c|c|}
\hline \multirow{2}{*}{ Fabric } & \multirow{2}{*}{ View } & \multirow{2}{*}{ Design Points } & \multirow{2}{*}{$\begin{array}{l}\text { Qipao } \\
\text { Mean (S.D.) }\end{array}$} & \multirow{2}{*}{$\begin{array}{l}\text { Hanfu } \\
\text { Mean (S.D.) }\end{array}$} \\
\hline & & & & \\
\hline \multirow{7}{*}{ Cotton } & Front & Collar & $4.62(1.40)$ & $4.53(1.60)$ \\
\hline & & Sleeve & $4.30(1.30)$ & $4.44(1.50)$ \\
\hline & & Xiejin & $4.48(1.60)$ & I \\
\hline & Side & Collar & $4.4 I$ (I.50) & $4.34(1.60)$ \\
\hline & & Sleeve & $4.17(1.50)$ & $4.29(1.80)$ \\
\hline & Back & Collar & $4.68(1.60)$ & $5.24(1.40)$ \\
\hline & & Sleeve & $4.35(1.50)$ & $4.63(1.50)$ \\
\hline \multirow{7}{*}{ Hemp } & Front & Collar & $4.14(1.60)$ & $4.52(1.50)$ \\
\hline & & Sleeve & $4.42(1.40)$ & $4.17(1.60)$ \\
\hline & & Xiejin & $4.34(1.50)$ & I \\
\hline & Side & Collar & $4.29(1.60)$ & $4.18(1.50)$ \\
\hline & & Sleeve & $4.67(1.46)$ & $3.94(1.60)$ \\
\hline & Back & Collar & 4.37 (I.55) & $3.69(1.80)$ \\
\hline & & Sleeve & $4.28(1.52)$ & $3.73(1.70)$ \\
\hline \multirow{7}{*}{ Silk } & Front & Collar & 4.17 (1.70) & $3.96(1.60)$ \\
\hline & & Sleeve & $4.59(1.60)$ & $4.34(1.40)$ \\
\hline & & Xiejin & $4.60(1.60)$ & I \\
\hline & Side & Collar & $4.63(1.60)$ & $4.05(1.60)$ \\
\hline & & Sleeve & $4.66(1.60)$ & $4.03(1.60)$ \\
\hline & Back & Collar & $4.61(1.60)$ & $4.70(1.50)$ \\
\hline & & Sleeve & $4.81(1.50)$ & $4.49(1.50)$ \\
\hline
\end{tabular}

Table 6 Two-way ANOVA results ( $p$-values) to test the effects of fabric type and design on overall appearance similarities in front, back and side (*The mean difference is significant at the 0.05 level)

\begin{tabular}{|c|c|c|c|c|c|}
\hline View & $\begin{array}{l}\text { Corrected } \\
\text { model }\end{array}$ & Fabric & Design & $\begin{array}{l}\text { Fabric } \\
\text { *design }\end{array}$ & $\begin{array}{l}\text { Post hoc } \\
\text { LSD test }\end{array}$ \\
\hline \multirow[t]{2}{*}{ Front } & $0.000^{*}$ & $0.001 *$ & $0.000 *$ & 0.313 & $(S=C)>H$ \\
\hline & & & & & Hanfu>Qipao \\
\hline \multirow[t]{2}{*}{ Side } & $0.000^{*}$ & $0.026^{*}$ & $0.000^{*}$ & 0.494 & $(\mathrm{~S}=\mathrm{C})>\mathrm{H}$ \\
\hline & & & & & Hanfu $>$ Qipao \\
\hline \multirow[t]{3}{*}{ Back } & $0.000 *$ & $0.009 *$ & $0.003 *$ & $0.000 *$ & $\begin{array}{l}\text { Qipao: } p<.05 \\
(S=C)>H\end{array}$ \\
\hline & & & & & $\begin{array}{l}\text { Hanfu: } p<.05 \\
(S=H)>(H=C)\end{array}$ \\
\hline & & & & & Hanfu>Qipao \\
\hline
\end{tabular}

For the overall appearance similarity in the front view, there was no significant interaction between the two independent variables, fabrics and design $(\mathrm{p}=.273)$. There was a significant effect of fabric type $(\mathrm{p}=.01)$, but no significant effect of design $(\mathrm{p}=.234)$. The result showed that cotton fabric's mean front similarity was highest and hemp fabric's mean front similarity was lowest. A post hoc Least Significant Difference (LSD) test showed that the fabric type can be classified into two groups from high to low: cotton and silk (no significant difference), silk and hemp (no significant difference).

For the overall appearance similarity in the side view, there was no significant interaction between the two independent variables $(\mathrm{p}=.35)$. There was no significant effect of fabric type $(\mathrm{p}=.47)$, but a significant effect of design $(\mathrm{p}=.014)$. The results showed that the Hanfu's mean side similarity was significantly higher.

For the overall appearance similarity in the back view, there was significant interaction between the two independent variables $(\mathrm{p}=.001)$. There existed a significant effect of fabric type $(\mathrm{p}=.018)$, but no significant effect of design ( $\mathrm{p}=.694)$. Table 6 presents the adjusted mean scores across the six cells. Because the interaction is significant, the researcher separated the two design conditions and conducted two one-way ANOVA tests on fabric types. There was significant effect of fabric for both the Qipao, $\mathrm{p}>.05$, and the Hanfu, $\mathrm{p}<.05$. For the Hanfu, the results presented that cotton fabric's mean back similarity was the highest and hemp fabric's mean back similarity was the lowest. A post hoc LSD test showed that the fabric type can be classified into two groups from high to low: cotton and silk (no significant difference), and hemp.

To test the effect of independent variables, fabric type and design on the appearance similarity of different design points, i.e, collar, sleeve, and xiejin (for Qipao only), the researcher conducted several two-way ANOVA tests for front, back and side. However, most of the ANOVA tests have significant interaction between fabric type and design. Also, the design of Qipao and Hanfu's collars and sleeves are different. Therefore, the researcher separated Qipao and Hanfu data and conducted one-way ANOVA tests to investigate the effect of fabric type on the appearance similarity on different design points. The p-value of one-way ANOVA tests is in Table 7.

For the front view appearance, there was no significant effect of fabric type on the Qipao collar ( $\mathrm{p}=.058)$, but there a significant effect of fabric type on the Hanfu collar ( $\mathrm{p}=.023)$; the results showed that the cotton fabric's mean for the Hanfu front-view similarity was highest and the silk fabric's mean was lowest. A post hoc LSD test showed 
that the fabric type can be classified into two groups from high to low: cotton and hemp (no significant difference), and silk. For the appearance in the front view, there were no significant effect of fabric type both on the Qipao sleeve, $p=.339$, the Hanfu sleeve, $p=.469$, and the Qipao Xiejin, $\mathrm{p}=.508$.

Table 7 One- way ANOVA Correlations between independent variables and appearance similarities (* The mean difference is significant at the 0.05 level)

\begin{tabular}{|c|c|c|c|c|}
\hline View & $\begin{array}{l}\text { Design } \\
\text { point }\end{array}$ & $\begin{array}{l}\text { Fabric } \\
\text { (Cotton, } \\
\text { hemp, silk) }\end{array}$ & Design & $\begin{array}{l}\text { LSD post hoc } \\
\text { results on } \\
\text { fabrics }\end{array}$ \\
\hline \multirow{5}{*}{ Front } & \multirow[t]{2}{*}{ Collar } & 0.058 & Qipao & I \\
\hline & & $.023 *$ & Hanfu & $(\mathrm{C}=\mathrm{H})>\mathrm{S}$ \\
\hline & \multirow[t]{2}{*}{ Sleeve } & 0.399 & Qipao & I \\
\hline & & 0.469 & Hanfu & I \\
\hline & Xiejin & 0.508 & Qipao & I \\
\hline \multirow{4}{*}{ Side } & \multirow[t]{2}{*}{ Collar } & 0.332 & Qipao & I \\
\hline & & 0.473 & Hanfu & I \\
\hline & \multirow[t]{2}{*}{ Sleeve } & $.036^{*}$ & Qipao & $(\mathrm{H}=\mathrm{S})>\mathrm{C}$ \\
\hline & & 0.329 & Hanfu & I \\
\hline \multirow{4}{*}{ Back } & \multirow[t]{2}{*}{ Collar } & 0.337 & Qipao & I \\
\hline & & $.000 *$ & Hanfu & $\mathrm{C}>\mathrm{S}>\mathrm{H}$ \\
\hline & \multirow[t]{2}{*}{ Sleeve } & $.022 *$ & Qipao & $S>(C=H)$ \\
\hline & & $.000 *$ & Hanfu & $(C=S)>H$ \\
\hline
\end{tabular}

For the side view appearance, there were no significant effect of fabric type both on the Qipao collar $(\mathrm{p}=.332)$, and the Hanfu collar $(p=.473)$. There was no significant effect of fabric type on the Hanfu sleeve $(p=.329)$, yet there existed significant effect of fabric type on the Qipao sleeve ( $\mathrm{p}=.036)$; the results showed that the hemp fabric's mean for the Qipao side-view similarity was the highest and the cotton fabric's mean was the lowest. A post hoc LSD test showed that the fabric type can be classified into two groups from high to low: hemp and silk (no significant difference), and cotton.

For the back view appearance, there was no significant effect of fabric type on the Qipao collar ( $\mathrm{p}=.337)$, but a significant effect of fabric type on the Hanfu collar $(\mathrm{p}=.000)$; the results showed that the cotton fabric's mean for the Hanfu back-view similarity was the highest and the hemp fabric's mean was the lowest. Also, there was a significant effect of fabric type on both the Qipao sleeve, $p=.022$, and the Hanfu sleeve, $p=.000$. For the Qipao sleeve, the result showed that the cotton fabric's mean for the back-view similarity was the highest and the hemp fabric's mean was the lowest. A post hoc LSD test showed that the fabric type can be classified into two groups from high to low: silk, and cotton and hemp (no significant difference). For the Hanfu sleeve, the results showed that the cotton fabric's mean for the back-view similarity was the highest and the hemp fabric's mean was the lowest. A post hoc LSD test showed that the fabric type can be classified into two groups from high to low: cotton and silk (no significant difference), and hemp.

As the results show in Table 6, the front and back view's p-values supported H1, but the side view's p-value did not support H1. Fabric type significantly affected the appearance similarity of the front and back view of multi-layered cultural garments. However, the similarity of the back view of garments has an interaction between fabric type and design, as shown in Figure 6. The researcher conducted two oneway ANOVA and found that fabric type significantly affected the Hanfu appearance similarity of the back view. The side view of virtual appearance representations was inaccurate; however, the data in Table 7 cannot offer a reasonable explanation. When the researcher went back to compare the physical and virtual garments pictures, the virtual garments were not accurate in the waist area. Therefore, although the side view's p-value did not support $\mathrm{H} 1$, the analysis results in general support H1.

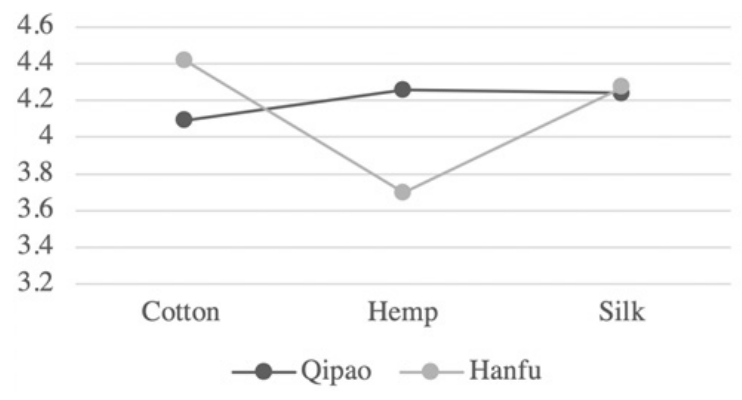

Figure 6 The interaction of the appearance similarity of back view of garments.

Further ANOVA analysis on selected points of measure found that the collar's front appearance, the Qipao sleeve's side appearance, the sleeve's back appearance, and the Hanfu collar's back appearance similarities' p-values were affected by the fabric type. Therefore, the fabric type significantly affected the front collar similarity, indicating that the fabric type significantly affected the front view in general. Additionally, the back view of sleeve similarity, contributes to the effect due to fabric type in the back view. However, the LSD post hoc results were different between the back views of the sleeve and the entire Qipao.

From two-way ANOVA, the side view's p-values supported H3, and the front and back's p-value did not support H2. Design significantly affected the appearance similarity of the side view in multi-layered cultural garments. The front and back view of virtual appearance representations were inaccurate based on the statistic result; however, the data in Table 7 cannot offer a reasonable explanation. This might have been attributed to the virtual simulation software's inability to represent the fabric wrinkles accurately. Overall, this research did not support H2. The result was different from previous studies by other researchers. ${ }^{8,19,32}$ One possible reason is that the sample used here was multi-layered cultural garments, and the structure for the cultural garments may be different.

Previous studies have support this result that fabric type affects the quality of garment appearance. ${ }^{12,14}$ They found that materials' mechanical properties would influence the quality of virtual garment appearance. However, Buyukaslan et al. ${ }^{33}$ found that fabric type did not affect the quality of the garment appearance. They found that the virtual simulation system did not represent the relationship between different fabrics and body shape. ${ }^{33}$

\section{Fit similarity quantitative analysis}

The mean and standard deviation data of fit similarity quantitative analysis are presented in Table 8 and Table 9 . The researcher analysed appearance similarity and fit similarity individually. For testing H3 and $\mathrm{H} 4$, two-way ANOVA tests were conducted to examine whether the two independent variables, fabric and garment design, significantly 
affected the appearance similarity in multi-layered cultural garments. The p-values of these two-way ANOVA test results are in Table 10. For the overall fit similarity in the front view, there was no significant interaction between the two independent variables $(\mathrm{p}=.313)$. There existed a significant effect of fabric type $(\mathrm{p}=.01)$, and design $(\mathrm{p}=.00)$. For design, the results showed that the Hanfu's mean front similarity was higher than the Qipao's. For fabric type, the results showed that the silk's mean front similarity was the highest and the hemp's mean front similarity was the lowest. A post hoc LSD test showed that the fabric type can be classified into two groups from high to low: silk and cotton (no significant difference), and hemp.

Table 8 The fit similarities for descriptive statistic of front, side, and back views

\begin{tabular}{|c|c|c|c|}
\hline \multirow{2}{*}{ Fabric } & \multirow{2}{*}{ View } & \multirow{2}{*}{$\begin{array}{l}\text { Qipao } \\
\text { mean (S.D.) }\end{array}$} & \multirow{2}{*}{$\begin{array}{l}\text { Hanfu } \\
\text { mean (S.D.) }\end{array}$} \\
\hline & & & \\
\hline \multirow{3}{*}{ Cotton } & Front & 3.51 (1.4) & 4.37 (I.3) \\
\hline & Side & 3.59 (1.3) & $4.42(1.4)$ \\
\hline & Back & $3.62(1.4)$ & $4.57(1.3)$ \\
\hline \multirow{3}{*}{ Hemp } & Front & $3.44(1.3)$ & 3.87 (1.4) \\
\hline & Side & 3.41 (I.3) & 3.97 (I.5) \\
\hline & Back & 3.89 (1.2) & $3.58(1.5)$ \\
\hline \multirow{3}{*}{ Silk } & Front & $3.87(1.3)$ & 4.53 (I.4) \\
\hline & Side & 3.77 (I.3) & $4.30(1.3)$ \\
\hline & Back & $3.93(1.4)$ & $4.34(1.5)$ \\
\hline
\end{tabular}

Table 9 The fit similarity for descriptive statistic of different design points

\begin{tabular}{|c|c|c|c|c|}
\hline \multirow{2}{*}{ Fabric } & \multirow{2}{*}{ View } & \multirow{2}{*}{$\begin{array}{l}\text { Design } \\
\text { points }\end{array}$} & \multirow{2}{*}{$\begin{array}{l}\text { Qipao } \\
\text { mean (S.D.) }\end{array}$} & \multirow{2}{*}{$\begin{array}{l}\text { Hanfu } \\
\text { mean (S.D.) }\end{array}$} \\
\hline & & & & \\
\hline & Front & Collar & $4.4 \mid(I .5)$ & $4.57(1.5)$ \\
\hline & & Sleeve & 3.99 (I.4) & $4.24(1.5)$ \\
\hline & & Xiejin & 4.67 (I.6) & I \\
\hline \multirow[t]{7}{*}{ Cotton } & Side & Collar & $4.4 I(I .4)$ & $4.33(1.5)$ \\
\hline & & Sleeve & $3.90(1.5)$ & 4.09 (1.6) \\
\hline & Back & Collar & $4.55(1.6)$ & $5.15(1.4)$ \\
\hline & & Sleeve & 4.23 (I.5) & $4.56(\mathrm{I} .6)$ \\
\hline & Front & Collar & 4.01 (I.6) & $4.34(\mathrm{I} .5)$ \\
\hline & & Sleeve & 4.40 (I.5) & 3.91 (I.6) \\
\hline & & Xiejin & 4.21 (I.6) & I \\
\hline \multirow[t]{7}{*}{ Hemp } & Side & Collar & $4.25(1.6)$ & $4.18(1.6)$ \\
\hline & & Sleeve & $4.62(1.4)$ & 3.81 (I.5) \\
\hline & Back & Collar & 4.47 (I.5) & 3.78 (I.7) \\
\hline & & Sleeve & $4.18(1.4)$ & $3.90(1.7)$ \\
\hline & Front & Collar & $4.10(1.6)$ & $3.94(1.8)$ \\
\hline & & Sleeve & $4.45(1.5)$ & $4.18(1.6)$ \\
\hline & & Xiejin & $4.53(1.5)$ & I \\
\hline \multirow[t]{4}{*}{ Silk } & Side & Collar & $4.49(1.6)$ & 4.09 (I.6) \\
\hline & & Sleeve & $4.7 I(I .5)$ & $3.92(1.5)$ \\
\hline & Back & Collar & $4.60(1.5)$ & $4.63(1.53)$ \\
\hline & & Sleeve & 4.7I (I.6) & $4.40(1.45)$ \\
\hline
\end{tabular}

Table 10 Two-way ANOVA results (p-values) to test the effects of fabric type and design on overall fit similarities in front, back and side $(*$ The mean difference is significant at the 0.05 level)

\begin{tabular}{|c|c|c|c|c|c|}
\hline View & $\begin{array}{l}\text { Corrected } \\
\text { model }\end{array}$ & Fabric & Design & $\begin{array}{l}\text { Fabric* } \\
\text { design }\end{array}$ & $\begin{array}{l}\text { Post hoc } \\
\text { LSD test }\end{array}$ \\
\hline \multirow[t]{2}{*}{ Front } & $0.000 *$ & $0.001 *$ & $0.000^{*}$ & 0.313 & $(S=C)>H$ \\
\hline & & & & & Hanfu>Qipao \\
\hline \multirow[t]{2}{*}{ Side } & $0.000^{*}$ & $0.026 *$ & $0.000^{*}$ & 0.494 & $(\mathrm{~S}=\mathrm{C})>\mathrm{H}$ \\
\hline & & & & & Hanfu>Qipao \\
\hline \multirow[t]{3}{*}{ Back } & $0.000^{*}$ & $0.009 *$ & $0.003^{*}$ & $0.000 *$ & $\begin{array}{l}\text { Qipao: } \mathrm{p}<.05 \\
(\mathrm{~S}=\mathrm{C})>\mathrm{H}\end{array}$ \\
\hline & & & & & $\begin{array}{l}\text { Hanfu: } \mathrm{p}<.05 \\
(\mathrm{~S}=\mathrm{H})>(\mathrm{H}=\mathrm{C})\end{array}$ \\
\hline & & & & & Hanfu>Qipao \\
\hline
\end{tabular}

For the overall side view fit similarity there was no significant interaction between the two independent variables $(\mathrm{p}=.494)$. There existed a significant effect of fabric type $(\mathrm{p}=.026)$, and design $(\mathrm{p}=.00)$. For design, the results showed that the Hanfu's mean side fit similarity was significantly higher than Qipao's mean side similarity. For fabric, the results showed that the silk's mean side similarity was the highest and the hemp's mean front similarity was the lowest. A post hoc LSD test showed that the fabric type can be classified into two groups from high to low: cotton and silk (no significant difference), and hemp.

For the overall fit similarity in back view, there was significant interaction between the two independent variables $(p=.00)$. There existed a significant effect of fabric type $(\mathrm{p}=.009)$, and design $(p=.003)$. For fabric type, the result showed that the Hanfu's mean back similarity was the highest and the Qipao's mean back similarity was the lowest (Table 10). Because the interaction is significant, the researcher separated the two design conditions and conducted two one-way ANOVA tests on fabric types. There were significant effects of fabric types for both the Qipao $(\mathrm{p}<.05)$ and the Hanfu $(\mathrm{p}<.05)$. For Qipao, the result showed that the silk's mean back fit similarity was the highest and the hemp's mean back similarity was the lowest. A post hoc LSD test showed that the fabric type can be classified into two groups from high to low: silk and cotton (no significant difference), and hemp. For Hanfu, the result showed that the silk's mean back similarity was the highest and the cotton's mean back similarity was the lowest. A post hoc LSD test showed that the fabric type can be classified into two groups from high to low: silk and hemp (no significant difference), and hemp and cotton (no significant difference).

To test the effect of independent variables, fabric type and design on the design points' fit similarities of different design points, several one-way ANOVAs were conducted (Table 11). In this study, the researcher described and tested the effect of fabric type on the appearance similarity at different design points (collar and sleeve). For the fit in the front view, there were no significant effect of fabric type for either the Qipao collar ( $\mathrm{p}=.667)$, or Hanfu collar $(\mathrm{p}=.065)$. Likewise, there was no significant effect of fabric type both for the Qipao sleeve ( $\mathrm{p}=.576)$, and Hanfu $(\mathrm{p}=.501)$. For the Qipao Xiejin, there was no significant effect of fabric type $(\mathrm{p}=.481)$. For the fit in the side view, there were no significant effect of fabric type both for the Qipao collar $(\mathrm{p}=.420)$, and Hanfu $(\mathrm{p}=.258)$. Nor was there any significant effect of fabric type both for the Qipao sleeve ( $p=.082)$, and Hanfu $(\mathrm{p}=.678)$. 
Table I I One-way ANOVA Correlations between independent variables and fit similarities ( $*$ The mean difference is significant at the 0.05 level)

\begin{tabular}{|c|c|c|c|c|}
\hline View & $\begin{array}{l}\text { Design } \\
\text { point }\end{array}$ & $\begin{array}{l}\text { Fabric } \\
\text { (Cotton, hemp, } \\
\text { silk) }\end{array}$ & Design & $\begin{array}{l}\text { LSD post hoc } \\
\text { results on fabrics }\end{array}$ \\
\hline \multirow{5}{*}{ Front } & Collar & 0.667 & Qipao & 1 \\
\hline & & 0.065 & Hanfu & l \\
\hline & Sleeve & 0.576 & Qipao & l \\
\hline & & 0.501 & Hanfu & I \\
\hline & Xiejin & 0.481 & Qipao & l \\
\hline \multirow{4}{*}{ Side } & Collar & 0.42 & Qipao & I \\
\hline & & 0.258 & Hanfu & l \\
\hline & Sleeve & 0.082 & Qipao & I \\
\hline & & 0.678 & Hanfu & I \\
\hline \multirow{4}{*}{ Back } & Collar & 0.421 & Qipao & 1 \\
\hline & & $.000 *$ & Hanfu & Hanfu: $(\mathrm{C}=\mathrm{S})>\mathrm{H}$ \\
\hline & Sleeve & 0.08 & Qipao & 1 \\
\hline & & $.001 *$ & Hanfu & Hanfu: $(C=S)>H$ \\
\hline
\end{tabular}

For the fit in the back view, there was no significant effect of fabric type for the Qipao collar $(\mathrm{p}=.421)$. There was a significant effect of fabric type for the Hanfu collar $(\mathrm{p}=.000)$; the result showed that the cotton fabric's mean for the Hanfu back-view similarity was the highest and the hemp fabric's mean was the lowest. A post hoc LSD test showed that the fabric type can be classified into two groups from high to low: cotton and silk (no significant difference), and hemp. There was no significant effect of fabric type for the Qipao sleeve $(p=.08)$. There was a significant effect of fabric type for Hanfu sleeve $(\mathrm{p}=.001)$; the result showed that the silk fabric's mean for the Hanfu back-view similarity was the highest and the hemp fabric's mean was the lowest. A post hoc LSD test showed that the fabric type can be classified into two groups from high to low: cotton and silk (no significant difference), and hemp.

For testing $\mathrm{H} 3$ and H4, two-way ANOVA and one-way ANOVA were used to examine whether fabric and design significantly affected the fit similarity in multi-layered cultural garments. The results are shown in Table 10, from the two-way ANOVA, the front, side and back view's p-values supported $\mathrm{H} 3$ and $\mathrm{H} 4$, which support the previous findings. ${ }^{18,34}$ Fabric type and design significantly affected the appearance similarity of the front, side, and back views in multilayered cultural garments. The simulation quality of loose fit multilayered garment (Hanfu) is better than the tight fit multi-layered garments (Qipao). However, the back view has an interaction between fabric type and design, as shown in Figure 7. The researcher conducted two one-way ANOVA and found that fabric type significantly affected both the Hanfu and Qipao appearance similarity of the back view.

Further ANOVA analysis on the selected design points found that the sleeve's back fit and Hanfu collar's back fit similarity's p-values were affected by the fabric type. Therefore, the fabric type significantly affected the sleeve in the back view similarity, proving that the fabric type significantly affected the back view. However, the LSD post hoc results were slightly different from the back view of sleeve similarity and the back view similarity. There are circumstances where fabric type and design significantly affected the appearance similarity of the front and side views, however, the data in Table 11 cannot offer a reasonable explanation. After comparing the physical and virtual pictures, the researcher concluded that the realistic fit presented in other areas, like waist and hip, makes the front, side, and back views visible. In addition, dyeing and washing clothes causes shrinkage, which may have influenced the results. In conclusion, $\mathrm{H} 3$ and $\mathrm{H} 4$ were supported by this study.

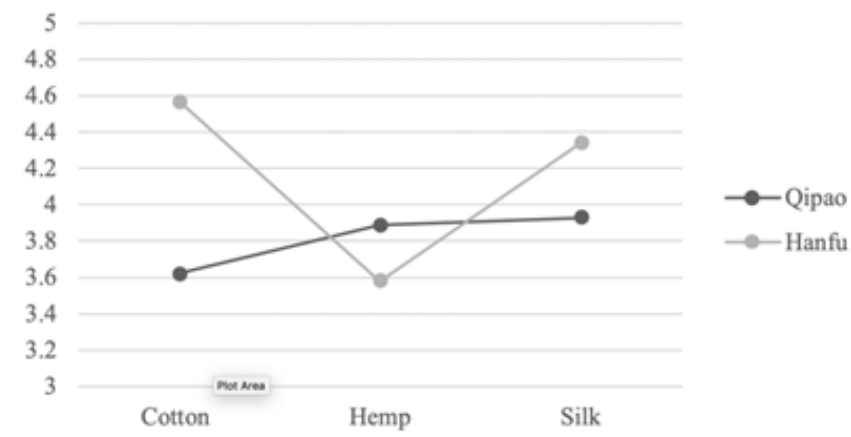

Figure $\mathbf{7}$ The interaction of the fit similarity of back view of garments.

\section{Conclusion}

This study analyzed the similarity of appearance and fit between physically constructed multi-layered cultural garments and those that are virtually constructed. First, this study found that multi-layered cultural garments could be relatively effectively simulated in virtual software, such as EFI Optitex. In addition, the simulation quality of a loose fit, multi-layered garment (Hanfu) is better than the tight fit multi-layered garments (Qipao). Therefore, this study suggested that the virtual simulation technology could be used for loose fit multilayered cultural garment. Second, fabric type significantly affects the appearance and fit similarity in multi-layered cultural garments (H1 \& H3). Therefore, the presented software could be used for garments with different kinds of fabrics. The quality of multi-layered virtual garments related to the materials. Third, design silhouette significantly affects the fit similarity in multilayered cultural garments (H4). Also, number of fabric layers does not significantly affect either appearance or fit similarity between virtual and physical garments. In addition, the researcher found that the results for fit similarity and appearance similarity were slightly different, specifically, the design silhouette does not affect the appearance similarity (H2). Besides, the researcher found the resolution function offer by the EFI Optitex to solve the penetration problem which is the general issue happened in the process of multi-layered garments simulation.

Based on these results it can be concluded that virtual presentation has great potential as a tool to evaluate the appearance of a garment in a relatively simple and quick way. One implication and conclusion from the study was about 3D simulation of non-western garments would be beneficial for the emerging market in China. A limitation of this study was that the researcher only tested two cultural garment types with three different fabric types using a single garment simulation software program. Also, dyeing and washing clothes might cause shrinkage, which may have influenced the results. While the software program was from a leading company, findings from this study cannot be generalized to other 3D simulation software packages.

Future studies should consider comparing several programs using different garment and more fabric combinations for complete testing 
of 3D virtual garment simulation fidelity and accuracy. In addition, since the current study only tested female garments, a full range of multi-layered garment types and fabrics should be tested. The physical draping simulation will facilitate the future use of more diverse types of materials for garment production. Therefore, by using $3 \mathrm{D}$ virtual prototyping, companies can reduce product development time and the cost involved in multiple iterations of sample garment production.

\section{Acknowledgments}

None.

\section{Funding}

None.

\section{Conflicts of interest}

The authors declare there are no conflicts of interest.

\section{References}

1. Ji Z. Research on the structure characteristic of "modern Hanfu" and digital implementation (Master dissertation). 2016.

2. Heine $\mathrm{K}$, Gutsatz M. Luxury brand building in China: Eight case studies and eight lessons learned. Journal of Brand Management. 2017;22(3):229245 .

3. Cobb K, Cao H, Davelaar E, et al. Physical to virtual: optimizing the apparel product development process to reduce solid waste in apparel. Proceedings of the International Textile and Apparel Association, St. Petersburg; 2017

4. Sayem AS. Objective analysis of the drape behaviour of virtual shirt, part 1: avatar morphing and virtual stitching. International Journal of Fashion Design, Technology and Education. 2017;10(2):158-169.

5. Bux K. Challenge reality: The shift from physical to virtual. 2014.

6. Sayem AS, Kennon R, Clarke N. 3D CAD systems for the clothing industry. International Journal of Fashion Design, Technology and Education. 2010;3(2):45-53.

7. Huang HQ, Mok PY, Kwok YL, et al. Block pattern generation: From parameterizing human bodies to fit feature-aligned and flattenable 3D garments. Computers in Industry. 2012;63(7):680-691.

8. Baytar F, Ashdown S. An exploratory study of interaction patterns around the use of virtual apparel design and try-on technology. Fashion Practice. 2015;7(1):31-52

9. Dennis C, Merrilees B, Kim J, et al. Adoption of sensory enabling technology for online apparel shopping. European Journal of Marketing. 2009.

10. Park J, Kim DE, Sohn M. 3D simulation technology as an effective instructional tool for enhancing spatial visualization skills in apparel design. International Journal of Technology and Design Education. 2011;21(4):505-517.

11. Naglic MM, Petrak S, Stjepanovič Z. Analysis of 3D construction of tight fit clothing based on parametric and scanned body models. 7th International Conference on 3D Body Scanning Technologies; 2016.

12. Rudolf A, Zadravec M, Stjepanovič Z. Investigations regarding the effects of simulating parameters during 3D garments' drape simulations. Fibres \& Textiles in Eastern Europe. 2016.

13. Lim H. Three dimensional virtual try-on technologies in the achievement and testing of fit for mass customization. 2009.

14. Ancutiene K, Sinkeviciutes D. The influence of textile materials mechanical properties upon virtual garment fit. Materials science. 2011;17(2):160-167.
15. Power J, Apeagyei PR, Jefferson AM. Integrating 3D scanning data \& textile parameters into virtual clothing. Hometrica Consulting. 2011:213224.

16. Luible C, Magnenat-Thalmann N. The simulation of cloth using accurate physical parameters. CGIM 2008, Austria: Insbruck; 2008.

17. Lee Y, Ma J, Choi S. Automatic pose-independent 3D garment fitting. Computers \& graphics. 2013;37(7):911-922.

18. Ancutiene K, Strazdiene E, Lekeckas K. Quality evaluation of the appearance of virtual close-fitting woven garments. The Journal of the Textile Institute. 2014;105(3):337-347.

19. Kim DE, LaBat K. An exploratory study of users' evaluations of the accuracy and fidelity of a three-dimensional garment simulation. Textile Research Journal. 2013;83(2):171-184.

20. Kim Y, Yin S, Song HK. A comparison of fit and appearance between real torso length sloper with $3 \mathrm{D}$ virtual torso length sloper. The research journal of the costume culture. 2014;22(6):911-929.

21. Kenkare N, Lamar TA, Pandurangan P, et al. Enhancing accuracy of drape simulation. Part I: Investigation of drape variability via $3 \mathrm{D}$ scanning. Journal of the Textile Institute. 2008;99(3):211-218.

22. Power J. Fabric objective measurements for commercial 3D virtual garment simulation. International Journal of Clothing Science and Technology. 2013

23. Wu YY, Mok PY, Kwok YL, et al. An investigation on the validity of 3D clothing simulation for garment fit evaluation. 2011.

24. Muhammad Sayem AS, Bednall A. A novel approach to fit analysis of virtual fashion clothing. 2017.

25. Hu P, Komura T, Holden D, et al. Scanning and animating characters dressed in multiple-layer garments. The Visual Computer. 2017;33(68):961-969.

26. Hu S, Wang R, Zhou F. Efficient penetration resolving in multilayered virtual dressing based on physical method. Journal of Fiber Bioengineering and Informatics. 2015;8(3):513-520.

27. Lazunin V, Savchenko V. Interactive visualization of multi-layered clothing. The Visual Computer. 2017;33(1):75-84.

28. Chew M. Contemporary re-emergence of the Qipao: political nationalism, cultural production and popular consumption of a traditional Chinese dress. The China Quarterly. 2007;189:144-161.

29. Jiang Y, Guo R, Hu J. Design and implementation of 3D qipao display system based on virtual reality technology. The Open Automation and Control Systems Journal. 2014;6(1):1785-1792.

30. Fan J, Yu W, Hunter L. Clothing appearance and fit: Science and technology. Elsevier; 2004.

31. Sayem AS. Objective analysis of the drape behaviour of virtual shirt, part 1: avatar morphing and virtual stitching. International Journal of Fashion Design, Technology and Education. 2017;10(2):158-169.

32. Tao X, Bruniaux P. Toward advanced three-dimensional modeling of garment prototype from draping technique. International Journal of Clothing Science and Technology. 2013.

33. Buyukaslan E, Jevsnik S, Kalaoglu F. Virtual fitting of a skirt on a parametric and a scanned body model. Marmara Fen Bilimleri Dergisi. 2015;27:23-26.

34. Song HK, Ashdown SP. Investigation of the validity of 3-D virtual fitting for pants. Clothing and Textiles Research Journal. 2015;33(4):314-330. 